\section{COVID-19 vaccination concerns among elderly people in Hong Kong}

Siukan Law, ${ }^{1}$ Albert Wingnang Leung, ${ }^{2}$ Chuanshan $\mathrm{Xu}^{3}$

${ }^{1}$ Department of Science, School of Science and Technology, The Open University of Hong Kong, Ho Man Tin, Kowloon, Hong Kong; ${ }^{2}$ School of Graduate Studies, Lingnan University, Tuen Mun, Hong Kong; ${ }^{3}$ Key Laboratory of Molecular Target and Clinical Pharmacology, State Key Laboratory of Respiratory Disease, School of Pharmaceutical Sciences \& Fifth Affiliated Hospital, Guangzhou Medical University, Guangzhou, China

\section{COVID-19 vaccination concerns among elderly people in Hong Kong}

Coronavirus disease 2019 (COVID19) outbreak occurred nearly a year, but it is continuous not under control up to the present. The 'Fourth wave' of pandemic just begins in Hong Kong and becomes more serious. More than a hundred people get an infection with COVID-19 per day and the death rate of elderly people is extremely high. On the $12^{\text {th }}$ of December in 2020, the Government of the Hong Kong Special Administrative Region announced that it has a vaccination program for three types of special people to receive the vaccination first, for example, elderly and chronic patients as they have greater mortality rates after infection with COVID-19. ${ }^{1}$ However, COVID-19 vaccination for the elderly still has some suspicions including: i) personal physique; ii) dosage and effective time; iii) side effect as well as the safety assessments.

i) As a few elderlies are declined the function of an immune system when the age increased, so-called immunosenescence results in diminished responses to vaccination. They cannot produce enough antibodies to combat the coronavirus and its body tends to be in a state of chronic low-grade inflammation. ${ }^{2}$ There is no inflammatory response when the severe acute respiratory syndrome-related coronavirus 2 infection (SARS-CoV-2) infects the respiratory tract. Hence,
COVID-19 vaccination is not suitable for some elderly.

ii) According to the Government of the Hong Kong Special Administrative Region, they have reached an agreement with Fosun Pharma to procure the COVID-19 mRNA vaccine (PfizerBNT162b2) developed by Fosun Pharma in collaboration with the German drug manufacturer BioNTech. This Pfizer-BNT162b2 vaccine has 2 doses series ( $30 \mu \mathrm{g}$ per dosage) within 21 days which are injected in the intramuscular deltoid muscle and achieved $90 \%$ of protection in seven days after the second dose. ${ }^{3}$ Besides, there is another vaccine developed by AstraZeneca in collaboration with the University of Oxford, called 'AZD1222'. It has a strong immune response and an effective rate of up to $90 \%$ if two full dosages are injected as the AstraZeneca vaccine stimulates broad antibody and $\mathrm{T}$ cell functions to have a better defense of the SARSCoV-2 infection. ${ }^{4}$

iii) Regarding the U.S. Food and Drug Administration (FDA), the major side effects of Pfizer-BNT162b2 vaccine such as injection site pain, fatigue, headache, muscle pain, chills joint pain, and fever. These unanticipated side effects from the first shot could deter people from going back, even the effectiveness jumped to $95 \%$ after the second. Side effects of vaccines are unusual. Fever is a signal for the immune system responding to the vaccine. This is the normal process to regulate the internal body function. The old adult experienced few side effects as they have a blunted immune response. In the early, two BNT162b2 recipients died and one AZD1222 recipient has neurological problems in clinical trials after vaccination. It is related to the recipients who got chronic diseases already but are not associated with the vaccination.

Should elderly vaccinate during the COVID-19 pandemic? What are the effectiveness and side effects of the vaccination? These types of suspicions cannot have detailed explanations in a short time. It is required much time and works to do the investigation. The major reasons for elderly vaccination are to prevent the COVID-19 infection and get a good immune system to defend the SARSCoV-2. However, they should consult with the doctor for safety before being vaccinated.
Correspondence: Siukan Law, Department of Science, School of Science and Technology, The Open University of Hong Kong, Ho Man Tin, Kowloon, Hong Kong.

E-mail: siukanlaw@hotmail.com

Key words: COVID-19; vaccination; elderly people.

Contributions: the authors contributed equally.

Conflict of interests: the authors declare no potential conflict of interests.

Received for publication: 20 Janaury 2021. Accepted for publication: 25 January 2021.

This work is licensed under a Creative Commons Attribution-NonCommercial 4.0 International License (CC BY-NC 4.0).

${ }^{\circ}$ Copyright: the Author(s), 2021

Licensee PAGEPress, Italy

Geriatric Care 2021; 7:9629

doi:10.4081/gc.2021.9629

\section{References}

1. The Government of the Hong Kong Special Administrative Region. Government announces latest development of COVID-19 vaccine procurement; 12 December 2020. Available from: https://www.info.gov.hk/gia/general/ 202012/12/P2020121200031.htm. Accessed: 21 December 2020.

2. Bridle BW, Sharif S. Why vaccines are less effective in the elderly, and what it means for COVID-19? 21 July 2020. Available from: https://theconversation.com/whyvaccines-are-less-effective-in-theelderly-and-what-it-means-for-covid19-141971. Accessed: 21 December 2020.

3. Gallagher J. Covid vaccine: First 'milestone' vaccine offers $90 \%$ protection; 9 November 2020. Available from: https://www.bbc.com/news/health54873105. Accessed: 21 December 2020.

4. Reuters. Early data show two doses of Oxford/AstraZeneca vaccine provoked good immune response; 18 December 2020. Available from: https://www.reuters.com/article/ukhealth-coronavirus-astrazeneca-oxfordidUKKBN28R2J8. Accessed: 21 December 2020

5. Polack FP, Thomas SJ, Kitchin N, et al.; C4591001 Clinical Trial Group. Safety and efficacy of the BNT162b2 mRNA Covid-19 vaccine. N Engl J Med 2020 [Epub ahead of print]. 